\title{
Common Expositional Problems in Students' Papers and Theses
}

Forrest D. Colburn, City University of New York

Norman Uphoff, Cornell University

\section{Norman Uphoff's Tips for Students' Papers}

A perennial topic of discussion among graduate students is the selection of a dissertation advisor. How do you pick one? What are the desirable attributes in a dissertation advisor? What are the undesirable attributes? Graduate students go around and around with criteria. Usually the discussion settles on a "Goldilocks solution": the desirable advisor offers neither too little guidance nor too much guidance. Everyone wants a worthy dissertation, but no student wants to pursue someone else's research agenda or be held up forever by an exacting (or disorganized) advisor.

Rarely discussed is something seen as decidedly pedestrian: the advisor's ability and penchant for offering detailed, written comments on drafts that refine the exposition, and, in the process, strengthen the student's skills at composition. It was my good fortune, more than 20 years ago, to have a dissertation advisor who not only offered exhaustive comments on my drafts, but who also took the time to teach me what I thought I already knew-how to write.

Looking back at my graduate studies in the department of government at Cornell University, I had wonderful teachers, including Richard Rosecrance, Peter Katzenstein, and Sidney Tarrow. But my most valuable teacher was my advisor, Norman Uphoff. Yes, I learned much about comparative politics from him. However, nothing I learned at Cornell has proved as valuable-in writing to date six university press books-as what Uphoff taught me about composition.

Over the years, Uphoff 's ability to read manuscripts critically and helpfully has become something of a legend among Cornell graduate students. Uphoff is skillful at organizing cogently ideas, a gift not easily codified. Given his pedagogical predilections, Uphoff has written a brief but very useful guide for students that addresses the most common flaws found in the many papers and theses that he has read over 40 years of teaching. The guide circulates widely on the Cornell campus, sometimes by fellow faculty members, but more often among students. It deserves even wider circulation.

$-F D C$

\section{DICTION-THE MOST IMPORTANT ELEMENT IN GOOD WRITING}

Words should be chosen and used carefully so that they convey the meaning or meanings that you intend-and do not convey any unintended or double meanings. Writing should leave little ambiguity or uncertainty about what you are referring to-unless some purposeful ambiguity is desired. Sometimes words that are abstract or superficial may be chosen to suit the writer's purpose. For example, there is a long tradition of euphemistic writing. But such use of words should be well-considered and deliberate, not the result of carelessness or indifference.

Good writing is done with what is called 'an economy of language,' using a minimum of words to convey one's meaning and purpose, avoiding complex sentence structure and also ornate, archaic or flowery language. Parsimony is a principle prized not only in the natural sciences. It is also a good criterion for social science and any other writing.

Choice of words-which is referred to as diction, hence the word dictionary-is the most important single aspect of good writing.

Forrest D. Colburn is a professor in the department of political science at the Graduate Center of the City University of New York and a visiting professor at the Latin American management school, Incae. He can be reached at Forrest.Colburn@

lehman.cuny.edu.

Norman Uphoff is professor emeritus of government and international agriculture at Cornell University. He can be reached at ntu1@cornell.edu.
Words should be selected purposefully, with clear reference to things observable or with a clear connection to the accepted language of discourse in your discipline or professional circles. In formal writing, such as in a term paper or thesis, avoid colloquial or slang expressions. Also, avoid contractions; these are acceptable in spoken English, but in formal writing they are appropriate only when reporting dialogue. Also, formal writing is usually in the third person, which minimizes first-person or second-person pronouns.

In any language, writing, like speech, can have several different levels (or degrees) of formality or informality. A very important part of effective communication is having a good ear, or a good sense, for what is the appropriate level or degree of formality (informality) for any particular communication.

\section{CONSISTENCY-THE SECOND MOST IMPORTANT ELEMENT IN GOOD WRITING}

When a writer does not pay attention to details, most readers will wonder what other details has the writer glossed over or simply not paid attention to? Inconsistency on minor matters undermines the readers' confidence in the author. They will wonder how carefully the author has dealt with other, more important matters of substance in his or her writing (and thinking). One doesn't need to be brilliant to be consistent, just disciplined and careful-which is expected of anyone with higher education. 
Ralph Waldo Emerson made a powerful and provocative assertion in his famous essay 'On Self-Reliance' that "Consistency is the hobgoblin of little minds." But he was not referring to writing, as his own was a model of discipline in writing and care in the choice of words, using the English language with deftness and consistency.

Consistency in punctuation, spelling and other features of one's writing is the second most important aspect of good writing. Of course, it is important to be correct. But being incorrect is compounded when a writer wobbles back and forth between correct and incorrect punctuation, spelling, format, headings, indentation, etc. Writers should strive to be both consistent and correct.

This advice applies to papers and theses, but even more to resumés and curricula vitae (CVs) since such documents give readers a quick impression of the writer's level of education and attention to format, details, etc. Many job opportunities are lost just because of sloppy CVs.

\section{Capitalization}

Capitalization of words in the text and in headings is often done haphazardly. Proper nouns, which refer to a particular/unique person, place or thing, should be always capitalized; while common nouns that refer to classes of things, rather than to a specific person, place or thing, are not capitalized. Contemporary writing styles are becoming more informal, so fewer words are capitalized these days. But for any particular word, once you have decided whether or not it will be capitalized, be completely consistent in capitalizing it (or not). In titles or headings, one does not capitalize minor words like the, and, or, in, or of.

\section{Headings}

Headings should be always consistent in form. This is often overlooked with regard to indentation, the use of upper and lower case letters, ${ }^{1}$ style of wording, italicization, etc. The wording and capitalization that are used in a table of contents should match the way that these same words are presented in the paper or thesis.

\section{Dates}

Dates are often written inconsistently, sometimes with the day put before the month and then sometimes put after it; sometimes using 'May 5th' and then later on 'May 5'; sometimes writing even '5th of May.' Inconsistency in the presentation of dates is disconcerting to attentive readers.

\section{A GRAMMATICAL CONSIDERATION}

An elementary rule of grammar is that the number of the subject of a sentence, whether it is singular or plural, must agree with its verb, whether this is singular or plural. This is often hard for nonnative English speakers to keep in mind; but surprisingly large numbers of native-writers of English get this wrong, forgetting just what are the subjects of their sentences. Making this mistake implies that the writer does not really know who or what he or she is talking about, i.e., who or what is the subject of the sentence, who is the actual actor or agent. Always be clear in every sentence that you write who or what is the subject-and make the verb agree with it.

An increasingly common mistake in written and spoken English is the use of plural pronouns to stand for singular nouns, e.g., 'the committee changed their (sic) decision from the previous meeting....' This might seem justified in some cases as sidestepping the issue of whether to use 'his' or 'her' or some variant thereof, since 'they' is without gender. However, 'they' is used mostly due to inattention or laziness, not gender-sensitivity. The way to decide whether to use a singular or a plural pronoun is to refer to whether the verb being used is singular or plural. Every pronoun should agree both with the relevant verb and with the noun for which it stands.

\section{PUNCTUATION}

\section{Quotation Marks}

Whether to place quotation marks outside or inside of other punctuation marks (periods and commas) causes a lot of trouble because American (US) and British (UK) styles differ in this matter. In American usage, quotation marks are put outside periods and commas, although not outside of colons or semicolons. When writing papers or theses for American readers (e.g., professors), Americanstyle punctuation should always be used, and used consistently. Numbers for footnotes also go outside periods and commas in American-style punctuation.

There is often confusion about when to use single quotation marks or double quotation marks. With any quotation within a quotation, one uses single marks inside and double marks outside. More generally, double marks (") are used when one is directly quoting some person, while single marks (') are used to set off a word being used with a particular meaning or connotation, but not as a direct quote from a particular person.

\section{Commas}

Commas are widely misused. Many writers seem to put them in wherever they would take a breath if they were speaking rather than writing. This is not the purpose for using commas. Commas should always be used (a) within complex sentence to set apart two sentence parts, each of which has its own subject and verb, and which are joined with an "and" between the two parts, or (b) to mark off dependent or subordinate clauses. Any clause in the middle of a sentence must both start and end with a comma, using commas in pairs.

For some clauses it will be optional whether to set its words apart from the main sentence with commas. Remember that if a comma is used either to start or to end a clause, then another comma must be used, to indicate the start of a clause or to close it. (Note: In the preceding sentence, a comma could have been put after the sentence's third word, clauses; because this is such a simple clause, there is no ambiguity, so putting in a comma is not necessary.) Whenever there could be any uncertainty about which words belong in the clause and which are part of the main sentence, one should put in a comma as a favor to the reader, eliminating any ambiguity.

A third and very common use for commas is (c) to set apart words in a series. When writing about more than two things in a series of simple, one-word items like apples, oranges and pears, there is no need for a comma before the 'and' that joins the last word in the series. However, when the things referred to are more complex, i.e., several words long, as with the series constitutional rights, civil liberties, and freedom of speech, a comma should be put before the 'and,' since 'civil' does not modify 'freedom,' but only 'liberties.' 
Commas are used to avoid any possible confusion or ambiguity. Writers should try to make the reader's task as easy as possible by minimizing any uncertainty about meaning. Commas should not be put into a sentence before parentheses; while this is often done, it is hard to think of a situation where this would be appropriate. In poorly written drafts, I generally find myself taking out about as many commas as I put in to make the writing more readable.

Wherever and whenever putting in a comma will make your meaning clearer, do this as a favor to readers, so that they will have no reason to pause and ponder, even for a split second, what you mean. A simple error, very common, is for writers to forget to close quotation marks or parenthetical or bracketed words, i.e., to use only one quotation mark, one parenthesis, or one bracket, and not two. These, unlike commas, always come in pairs.

\section{PARAGRAPHS}

Whenever writing, thought should be given to how to break the presentation of content into meaningful paragraphs. This is best done if the writer initially prepares an outline so that he/she knows the substance and sequence of what will be presented. Paragraphs should never be just a single sentence; conversely, they should not run on and on.

Every well-organized paragraph begins with a topic sentence. This introduces what is being communicated in the rest of the paragraph that follows. As a rule, paragraphs should never be longer than half a page in length, and $3-4$ paragraphs to a page is a reasonable norm. There is always a burden of proof on the writer for writing a paragraph that runs longer than half a page, although this is occasionally justifiable. A paragraph that runs for a whole page (or more) indicates the writer has not approached the subject analytically. Breaking up a long paragraph into two or three paragraphs, making one or more key sentences within it into topic sentences, so that these sentences stand out, enables them to communicate more than if they are buried in the middle of a long paragraph.

\section{SPACING}

Periods should always have at least one space after them. It is an acceptable style to have two spaces after a period that ends a sentence. However, most publishers want only one space after periods in manuscripts that will be printed. In bibliographies, as a matter of style, one can omit spacing after the periods abbreviating first names (F.H. Jones), but it may be considered less attractive. In any case, be consistent on spacing.

Spacing between sections must first of all be consistent. There is some degree of choice. Normally one leaves some extra space between sections that are separated by a heading or subheading. The proofreading sign that indicates a space-to be inserted or removed-is a pound sign (\#). When this symbol is put into the text by an editor, it is an instruction to add more space. If a \# sign is shown with a delete mark, this means to take out some or all of the space.

\section{SPELLING}

Writers often mix American and British spellings. When writing for courses or readers at an American university, American spelling should be used, e.g., 'labor' instead of 'labour,' and 'behavior' instead of 'behaviour.' Some British spellings such as 'judgement' instead of 'judgment and 'acknowledgement' instead of 'acknowl- edgment' are acceptable, but not preferred in American writing. British spellings can of course be used in direct quotes or in proper nouns, e.g., London Harbour.

Two common mistakes are to mix up 'affect' and 'effect' (if you don't know the difference, look it up), and 'foregoing' and 'forgoing' (the difference between the prefixes "fore-" and "for-" often gets confused). It is good to use the Spellcheck command on a word-processing program, but do not trust it. There are a multitude of mistakes that can slip through a Spellcheck, some of them hilarious or egregious. So use it, but with caution.

\section{ABBREVIATIONS AND ITALICIZATION}

The following abbreviations from Latin language are often written incorrectly:

- i.e.-which means 'that is' (sometimes written archaically as viz. in British usage), and

- e.g.-which means 'for example.' Both abbreviations need periods after both letters. Also, there should be a comma after the abbreviation, to set it off from the rest of the sentence: i.e., and e.g., On the other hand:

- et al.-which means 'and others'-has a period only after al. because this word is an abbreviation for the Latin term alia or alii, which means 'others.' There is no period after et because this word means 'and' and is not an abbreviation!

- op. cit.-means 'cited above' and has two periods; it is usually used only in footnotes

- ibid.-stands for ibidem and means 'in the same place.' This abbreviation is often used in footnotes where the reference just cited is being cited again, so that the full reference need not be repeated. The term ibid. means essentially the same thing as 'ditto.'

Traditionally, all of these Latin-derived terms and their abbreviations were italicized or underlined (which was a surrogate for italicization). These days, such stylization is less common. I do not expect the Latin abbreviations to be underlined or italicized because they have become integrated into the English language. Remember that these abbreviations should have a comma following them, such as in any clause that begins with i.e. (i.e., one can learn ...) or with e.g. (e.g., the first sentence in the paragraph ...).

Since italicization is so easy to do with most word-processing programs, there is now little reason to underline words. Published titles get italicized in the text and in a bibliography, as do foreign words to indicate to readers that these words are not English.

\section{HYPHENATION}

Hyphens are usually underutilized as modern style (or laxity) is reducing their usage. However, for readers' sake, it is good to use a hyphen whenever a compound noun or compound adjective is being used or created. The general rule for hyphenating compound adjectives is to use a hyphen whenever either word by itself, i.e., when standing alone, conveys a different meaning than when the words are used together, i.e., when they create a meaning that is different from their separate and respective meanings.

When writing about 'the long run,' there is no hyphen between long (adjective) and run (noun), because 'long' modifies 'run.' However, a hyphen should be used when writing about a longrun (adjective) trend (noun), because this meaning is different from either 'a long trend' or 'a run trend.' Here one is referring 
to a particular kind of trend, i.e., 'a long-run trend' with 'longrun' being a word different from its components, 'long' and 'run.'

When three or more words make up a compound adjective, there is even more reason to hyphenate them, as in 'a state-of-theart presentation.' Where an adverb that ends in -ly is used to modify an adjective, no hyphen is needed, as in 'a relatively long speech.' Also, 'well' as an adverb need not be hyphenated with an adjective, as in 'a well traveled road,' although this is easier to understand if written as 'a well-traveled road.' 'Well-traveled' has its own meaning, distinct from 'well' or 'traveled' because a compound meaning is intended.

Some terms are very well established as a set of words, such as the expression "face-to-face" or its French equivalent vis-á-vis. These are almost always hyphenated. In contrast, "matter of fact" is an idiom rather than a single expression, so it generally is not hyphenated.

It is a matter of choice whether to hyphenate a compound noun like "decision-making." Certainly it should be hyphenated whenever it is used as a compound adjective, as in "decision-making procedure." I favor hyphenating such compound nouns. But writers can choose not to hyphenate them, as long as they are consistent. Writers these days tend to use hyphens less frequently than did their predecessors; however, every so often they revert to traditional use and put in a hyphen. For the sake of consistency, it would be better for them to hyphenate that compound word throughout the text than to wobble back and forth in their use of the hyphen.

Another use for a hyphen is to break words at the end of a sentence. Some word-processing programs have a special feature to do this automatically, but often they do this incorrectly. Words should be hyphenated only according to their syllables, and we often have difficulty remembering a word's syllables correctly. When unsure where to break a word, consult a dictionary to be certain about being correct. Mistaken hyphenations sometimes break words at the end of sentences into false syllables, e.g., 'grumble' instead of 'grum-ble.' A rule governing this is that syllables of one or two letters should not be separated from the rest of the word.

\section{FOOTNOTES}

Superscript (raised) numbers for footnotes should be placed where they key the footnote to the relevant reference in the text. But it is best to do this in a way that interrupts the reader's train of thought as little as possible. Thus, I suggest that as a rule, footnote numbers should be placed at the end of the sentence, or at the end of the clause, rather than being inserted in the middle of a sentence or in the middle of a clause. Sometimes, it will be appropriate, i.e., not awkward, to attach the footnote number directly to a particular word within the sentence or clause to avoid any possible ambiguity. But this should be done only when avoiding ambiguity overrides the preference for not interrupting readers' comprehension of the sentence.

The form for citations of referenced publications in footnotes is not the same as for the bibliography. In the latter, authors are cited with their last name first, to facilitate finding them in alphabetical order. In footnotes, authors should be cited first name first. When in doubt about format for citations of references in footnotes and/or bibliographies, take some published work (book or journal article) that you find attractive and helpful, and use its style as a model. Then be absolutely consistent in following that style.

It is becoming optional whether, in bibliographies or footnotes, to italicize the published titles of references being listed or cited. But remember that what should get italicized, if this is the style you choose, is the published title. A journal name gets italicized, but not the title of the article being cited. The same rule applies for a chapter within a published book; only the book title is italicized. The title of the journal article or of the book chapter may or may not be enclosed in quotation marks. The moremodern style is not to use quotation marks around the titles of journal articles and book chapters.

\section{TWO COMMONLY MISUSED WORDS}

The prepositions 'between' and 'among' are often confused. 'Between' refers to two things, while 'among' refers to three or more. Most people know this intuitively, but they do not know (and thus do not always follow) this rule of diction.

Another common mistake is to put an apostrophe into the possessive pronoun its, writing the word as it's. The latter spelling is properly used only as a contraction of it is, something quite different from the possessive pronoun its, which has no apostrophe. Be sure always to use an apostrophe whenever writing a noun that is used with a possessive meaning, e.g., people's organizations.

\section{PICKY POINTS?}

Two traditional rules are weakening. Writers should know about these rules and should follow them whenever it is easy to do so, thereby showing that they are knowledgeable about such points. But these rules are no longer a big deal for most readers.

First, it used to be said that one should never end a sentence with a preposition. But Winston Churchill appropriately mocked and discredited this rule by exclaiming once: "Madam, that is a rule up with which I will not put!" The rule is a reasonable one, but it need not be adhered to rigidly. If the rule produces an awkward sentence, it should be ignored. Usually a sentence is more compact and more easily intelligible if it does not have a preposition dangling at its end.

Second, these days, few people seem even to know any more what constitutes a split infinitive. This term refers, when using the infinitive form of a verb, to separating the preposition 'to' from the verb with which it is associated, such as in the infinitive form 'to think.' Writing 'to cleverly think' instead of 'to think cleverly' is easily seen as an inelegant usage. On the other hand, to write 'to boldly go' rather than 'to go boldly' is an example of splitting an infinitive that does not sound objectionable or obtuse. The television series and movie Star Trek have made this split infinitive acceptable and immortal.

Splitting an infinitive often makes little difference stylistically, such as "to swiftly stride across the stage" compared to "to stride swiftly across the stage." While the latter is the grammatically preferred construction, the former is quite acceptable, and may even be thought to give some color to the expression. When either construction sounds equally cogent, it is a good idea to avoid splitting an infinitive. However, there are many circumstances when splitting the infinitive sounds better than keeping it intact. Writers should know about and think about split infinitives enough so that when they do split one, it is a matter of choice, not inadvertence. 


\section{SOME MISCELLANEOUS POINTS}

\section{Numbers}

The rule that I prefer is that the numbers 1 through 10 should be written out as words, i.e., one through ten, while numbers from 11 and higher get written as numerals. Of course, any number used to start a sentence needs to be written out, no matter how large or small. The Chicago Manual of Style would have us write out all numbers up to one hundred, but that seems old-fashioned these days.

The main rule is to be consistent. When numbers are used with units of measurement, it is fine to write them as numerals even if small, 1 percent or 5.3 miles, so long as the style is consistent throughout. Compound numbers, including fractions, should be hyphenated: Twenty-two seniors graduated in May, and onethird of the graduating class received honor degrees.

\section{Acronyms}

One thesis that I remember reading charmingly referred to these as "anacronyms." The first time that you refer in a text to an organization (or whatever) which has a well-known or sensible abbreviation, its name should be written out in full, with the acronym put in parentheses directly following the name. For example: The American Civil Liberties Union (ACLU) filed a suit...' Thereafter, one can write just the acronym.

When many acronyms are used in a paper or thesis, it is helpful for readers to have the names written out in full from time to time, e.g., the first time that the term is used in a chapter, reminding readers what the letters or compacted name stand for. Some style books stipulate that the name should be written out in full the first time it is used in any chapter. This is sensible if done consistently. But I consider this optional. If many acronyms are used in an article or thesis, a glossary of acronyms should be provided as a service to readers.

\section{Contractions}

Contractions should not be used in formal writing such as a thesis or research paper, unless directly quoting someone who is speaking in colloquial language. For example, write out 'is not' rather than write 'isn't.' Colloquial language should be kept to a minimum in course papers and theses.

\section{Dangling Modifiers}

Dangling modifiers are a common problem that I won't try to discuss here. On this and any other questions of usage, writers are referred to the classic guide by Strunk and White, The Elements of Style, first published in 1918. This is the standard text and arbiter for such questions. Everyone should be acquainted with this book, and most graduate students buy it and keep it handy on a shelf near where they work, i.e., write.

\section{Spurious Precision}

Spurious precision is something that is in vogue, and something of which everyone should be conscious. Often published sources give ridiculous numbers, which sometimes must be respected if quoting them. But in writing, it is permissible, in my view, to round off precise numbers that serve no purpose. A recent paper for my course said that $56.3 \%$ of the population live 'below the poverty line,' and that $40.4 \%$ of the labor force are subsistence farmers. Poverty lines are always ambiguous and a matter of much contention, and 'subsistence' is a matter of degree rather than kind. Who can know whether the number of persons 'in poverty' is $56.3 \%$ or $56.5 \%$ ? Or who can say that the number of subsistence farmers is $40.4 \%$ rather than $40.2 \%$ or $40.6 \%$ ? Nobody knows!

It is a mark of sophistication to use appropriate approximations rather than to cite exact but obviously silly numbers. One can write fairly confidently that over half of the population live below the poverty line in that country, or that $40 \%$ of the labor force are subsistence farmers. But even most census numbers, exact to the last person, are seldom, if ever true because of errors and omissions in the surveys. So, do not feel obliged, unless you are quoting someone else's number, to perpetuate mythical precise numbers. (Above, one could have written 'half of the population lives ...' if referring to 'the people' meaning they rather than to the population as it. This is a place where the writer could use either the singular or plural form of the verb.)

\section{Metaphors}

Writing would be much less interesting and communicative if there were no metaphorical use of words. But there can be too much of a good thing. Reflexive rather than purposeful use of metaphors makes for hackneyed writing. And when words are being used to evoke lively images or associations, they should be used with appreciation of all their implications and connotations. 'Mixed metaphors' are annoying indications that the writer is oblivious to or obtuse regarding the full scope of words and to their specific bundles of meanings. 'Bundles' is a metaphor here, not to be taken literally.

Recently, a student wrote in a paper about 'paving a project ...' when he would more appropriately have written 'paving the way for a project ...' meaning to make its progress easier and smoother. I tried to imagine what it means to 'pave a project.' One can pave the way for a project, but not the project itself. One might evocatively employ the images and associations of 'paving' in a particular statement about a project; but this word, like all others, should be used with appreciation of its various meanings and historical associations to enrich the content of communication.

Another recent paper referred to a minority ethnic group in Chile as "one of the lowest rungs on the social ladder." While people can be on one of the lowest rungs of a ladder, because they are people (not wood or metal), it is hard to imagine them as actually being rungs. One can imagine poor people being on rungs, and being stepped on by others climbing up the (metaphorical) social ladder, but it is wrong to describe the people themselves as rungs. Good writers use metaphors but use them aptly.

\section{Gratuitous Interjections and Gee-Whiz Comments}

Interjections like 'I think' or 'I believe' should be avoided since, presumably, you do not write anything that you do not think or believe. Statements like 'to be perfectly frank' or 'to be honest' are particularly egregious in writing because they imply that the writer is not always frank or honest and is writing duplicitously unless stating otherwise. Such interjections implicitly cast doubt on an author's veracity. Further, writing has more credibility when there is minimum, careful use of superlative forms, and when words like 'awesome' and 'amazing' are avoided. These are what I call 'gee-whiz' words.

The British norm of understatement is still valid in written communication. It is best to let one's data and precise descriptions 
convey to readers the magnitude or proportions of a situation, without editorializing words which have no weight in themselves, just expressing opinion. Adverbs like 'really,' 'truly' and 'very' add little to the persuasiveness of a statement. And the word 'obviously' is self-evidently redundant because if something is indeed obvious, it should be apparent to readers already.

\section{Et cetera}

Some persons dislike the use of etc. at the end of a series or sentence, thinking that it sounds vague and lazy. My own view is that there are times when etc. is appropriate and acceptable, e.g., if you know what else could be listed but you think that listing everything would be a burden to the reader. In general, I agree that there should be a burden of proof on the writer for using this abbreviation. Etc. should not be used because of the laziness of the writer, but it can be used out of consideration for the readers, especially if it can be assumed that the reader knows or has some good idea of what is represented by the term 'etc.'

\section{AN AMBIGUOUS POINT}

I am still often uncertain about when to use which and when to use that at the start of a clause. One of my students who pays attention to grammar says that the proper rule is to use 'which' when introducing a subordinate clause, and 'that' (which can also introduce subordinate clauses) when the reference is not subordinated: "The issue that was debated in the Senate was ..." in contrast to "The Senate debated an issue, which was hotly contested by the opposition party, without any final resolution." It would not be unreasonable to use 'which' in the first sentence or 'that' in the second. However, I agree that what is written in these two examples seems to sound best. The grammar software provided with Microsoft Word is 'anti-which.' This is inducing me to use "that" now more often than I did before. Still, the two words are reasonably interchangeable.

\section{AN UNFORTUNATE SEMANTIC SHIFT}

In the English language, the pronoun who refers to persons, while the pronoun that refers to things. The first is a personal pronoun, referring to one or more people, i.e., animate subjects or objects, and the latter is an impersonal pronoun, which refers to inanimate things. (Note: in this sentence 'which' definitely sounds better than 'that.') However, this distinction seems to be disappearing in common use.

Who is often being replaced by that as a matter of carelessness. If you pay attention to this, you will find that people frequently use the word that when they should be writing or saying who. (This is done more often in speech than in writing.) People never make this mistake when they use pronouns in their dative form. Nobody says (yet): "To that did you speak?-instead of "To whom did you speak?"-although some persons will say, incorrectly, "To who did you speak?" instead of "To whom did you speak?" The dative (indirect) form of nouns and pronouns, so evident in many other languages, often gets ignored in English.

We often hear or read sentences such as: "The Senator that (sic) made the speech ..." or "The policemen that (sic) made the arrest ..." or "The teacher that (sic) stood in front of the class ..." In all these sentences, who is required for proper English usage because Senators, police and teachers are people, not things!

The loss of this distinction between personal and impersonal pronouns is pervading the English language like a verbal virus.
Indeed, some people are starting to use the pronoun who to refer to things like foundations or companies, which is a further displacement of language. Remember: if someone knocks on your door, you never ask: "That's there?" You always ask: "Who's there?" So why is the pronoun that used so often now instead of who when referring to a person? I have no idea. Let's move now beyond such details.

\section{A SUGGESTION ON STYLE, AND FOLLOWING VS. BREAKING RULES}

From time to time it is useful to read a brilliant essay by George Orwell entitled "Politics and the English Language," written in 1946 but still relevant today. It is included in the paperback anthology of his essays, Shooting an Elephant and Other Essays. (It is also available online.) I find it helpful to re-read this essay every few years to reinforce my own sensibilities about good writing.

Orwell concluded his essay with six rules, the last of which was: "Break any of these rules sooner than say anything outright barbarous ... One can keep all of [the rules] and still write bad English." Similarly, the Dalai Lama once advised: "Learn the rules so you know how to break them properly." For good writing, there is ultimately no substitute for having a good ear for language and for its common usage, augmented by thoughtful attention to the choice of words and a healthy respect for the conventions of punctuation, grammar and so forth.

The way that words are used in various combinations is formally referred to as syntax: the rules or patterns of relationships that govern the way in which the words in a sentence come together. Syntax can and should vary according to one's audience to communicate most effectively. We instinctively adjust or modify our style of communication to suit the expectations and the listening or reading habits of those with whom we want to communicate. This is done, for example, by varying the complexity of sentence construction, or by choosing to use mostly common (colloquial) words or more sophisticated ('academic') terms.

It is too glib to say that 'rules are meant to be broken.' Rather I would suggest that rules organize and discipline our communication in useful ways, making it both more efficient and more effective. If rules are mastered-inculcated as habits or as engrams in our thinking-then knowing and using them reflexively, fluently, effortlessly, allows us to focus our creative efforts on the substance of what we want to convey, and enables us to avoid introducing awkward 'innovations' in forms that are distracting or confusing to readers and listeners.

Having forms of communication that are widely agreed upon and easily understood makes it easier for us to convey the content that we intend. Inconsistency or aberrations in form introduce a kind of 'noise' into communication that diminishes our success in communicating. Thus rules of usage should be considered as empowering rather than as confining. Being a good writer is like being a good athlete, who benefits from training, discipline, keeping in shape-and from knowing the rules. Really good athletes are very creative and effective within the rules, benefiting from training and discipline.

\section{ADVICE ON MULTIPLE DRAFTS}

The most helpful single way that one can improve one's writing is to take it through several drafts. First drafts are just that, a first attempt to put your ideas into written form that will be communicative, persuasive, even elegant. Nobody gets everything right 
the first time, although some persons produce better first drafts than do others.

If a first draft is put aside for a while, sometimes even for just a few hours, and is then re-read, to make improvements, many opportunities for this will surely appear to the writer. It is invariably disappointing, but we hope not too demoralizing, to see in each successive re-reading and re-drafting that the earlier draft can be considerably improved, for clarity, readability, effectiveness.

With some effort, a writer's product can approach some degree of refinement asymptotically through each review and re-writing, even though it is unlikely ever to achieve perfection. Clarity, readability and effectiveness are more reasonable criteria for assessment than perfection. I know that every time I look at my own writing, even in a fifth- or sixth-draft form, I find some things that can be written more felicitously, more clearly, more economically. This prompts me to try to make continuous, incremental improvement.

At some point, all written products have to be considered ready for circulation or submission. None will be perfect, but they should be products that one can be reasonably proud of and can stand behind. The 'trick' is to develop a schedule for one's writing so that there is enough time allowed to make at least a second review of the presentation-and if possible, a third or fourth—-to do whatever polishing, shortening, reorganization, elaboration, etc. seems appropriate.

Remember that 'the best is enemy of the good.' Perfection is beyond us. It is humbling to think of how many times I have gone through this note and have found wordings to improve, headings to revise, and paragraphs to reorganize. But better writing is always within our reach, through attentiveness to detail, effort made in good faith, mastery of the kind of rules and advice offered above, and dedication to good writing as a personal and professional value.

\section{WRITING AND IMAGINATION}

Efforts to make one's writing more effective and appreciated need not be considered arduous or diminishing. 'The joy of writing' lies in the continuous challenge to connect one's knowledge and one's imagination, also connecting one's knowledge and command of language, on one hand, with the needs, interests and expectations of readers, whether one's professor or colleagues or the general public, on the other.

One of Albert Einstein's most memorable and instructive quotations was: "Imagination is more important than knowledge." The process of writing operates at the interface between knowledge and imagination and, at the same time, at another imagined interface, between yourself and others. Effective writing requires knowing about those for whom you are writing-what they already know, what they expect from you-so that you do not waste your time and theirs by telling them things they do not need to know or do not want to know. Writing involves also knowing yourself, knowing what you know and what you do not know, so that you can build on the former and work carefully around the latter. I advise students to focus on what they know rather than what they do not know, making the most of what they know, and avoiding being immobilized by what they do not know.

There are very strong strictures and even penalties against plagiarism-taking others' words and thoughts and presenting them as one's own. It is acceptable to use others words and thoughts but only with proper citations and giving others full credit for what was their production and creation.

Writing is a kind of dance between knowledge and imagination. Practically all forms of dance have conventions and rules which dancers are expected to observe. But there is also encouragement for dancers to do some improvisation and some, maybe much, individualization within those rules. The analogy between dancing and writing is not complete or perfect, but it should give everyone encouragement. Everyone should know that in writing as in dancing, practice improves performance, and further that mistakes (missteps) are generally readily forgiven if they are made in the course of striving to improve.

\section{NOTES}

1. This distinction refers to capital versus uncapitalized letters, respectively. This terminology derives from the time when the text of books and newspapers was typeset by hand, when individual elongated blocks of lead-each with a raised reversed letter on one end-were set in a line of type to produce words for printing. Capitalized lead letters were kept in a set of boxes placed above the set of boxes from which the typesetter could take uncapitalized letters, to set in a line of type. Hence, we get the terms upper case for capital letters and lower case for uncapitalized letters. The proofreading designation 'caps' is fairly easy to understand, but ' $\mathrm{lc}$ ' (for lower case) is mysterious to anyone who does not know the history of typesetting and printing.

Editor's Note: Clarity, precision, and consistency, as noted in this article, are central to good writing. When preparing a final manuscript for publication, a style guide should be consulted. Different disciplines, as well as media and outlets, have different style guides, e.g., Associated Press Stylebook and Libel Manual, The Council of Science Editors Manual for Authors, Editors, and Publishers, Modern Language Association Style Manual and Guide to Scholarly Publishing, New York Times Manual of Style and Usage, Publication Manual of the American Psychological Association, and United States Government Printing Office Style Manual, that specify their rules of punctuation, hyphenation, capitalization, and citation; be sure to find out what style guide should be used in preparing your final manuscript. For example, PS: Political Science and Politics generally follows Chicago Manual of Style, 16th Edition, with some modifications. Also, publications and organizations have specific submission guidelines.- $\mathrm{R} \mathrm{J-P} \mathrm{H}$

\section{REFEREN CES}

Chicago Manual of Style: An Essential Guide for Writers, Editors, and Publishers, 16th Ed. 2011. Chicago: University of Chicago Press

Orwell, George. 1946. "Politics and the English Language." Horizon 13 (76): 252-65 also available online.

Strunk, William. 1918. Elements of Style. Ithaca, NY: Priv. print. [Geneva, NY: Press of W.P. Humphrey], 1918; Bartleby.com, 1999. www.bartleby.com/141/. [Accessed January 23, 2012.] 